Huining Pei $i^{1}$

Suihuai $\mathrm{Yu}^{1}$

Kari Babski-Reeves ${ }^{2}$

Jianjie $C h u^{1}$

Min $Q u^{1}$

Baozhen Tian ${ }^{1}$

Wenhua $L i^{1}$

\title{
QUANTIFICATION OF LOWER EXTREMITY PHYSICAL EXPOSURES IN VARIOUS COMBINATIONS OF SIT/STAND TIME DURATION ASSOCIATED WITH SIT-STAND WORKSTATION
}

\author{
${ }^{1}$ Northwestern Polytechnical University, Xi'an, China \\ Shaanxi Engineering Laboratory for Industrial Design \\ ${ }^{2}$ Mississippi State University, Mississippi, USA \\ Department of Industrial and Systems Engineering
}

\begin{abstract}
Background: Sit-stand workstations are available for office work purposes but there is a dearth of quantitative evidence to state benefits for lower limb outcomes while using them. And there are no guidelines on what constitutes appropriate sit/stand time duration. The primary aim of this study has been to compare muscle activity and perceived discomfort in the lower extremity during various combinations of sit/stand time duration associated with a sit-stand workstation separately and to evaluate the effects of the sit-stand workstation on the lower extremity during the text entry task. Material and Methods: During the 5 days, all participants completed a 2-h text entry task each day for various sit/stand time duration combinations as follows: 5/25 min, 10/20 min, $15 / 15 \mathrm{~min}, 20 / 10 \mathrm{~min}, 25 / 5 \mathrm{~min}$. Lower extremity muscular exposure of 12 male and 13 female participants was collected at 8 sites by surface electromyography and body discomfort was calculated by a questionnaire under those 5 conditions. Results: Results have demonstrated that lower extremity muscle activity has been significantly varied among the 5 sit/stand time duration groups. Perceived level of discomfort (PLD) has not differed significantly for 9 out of 10 body parts. Conclusions: The muscle activity of the thigh region was influenced by sit/stand time duration significantly. Ergonomic exposures of lower extremity when using a sitstand workstation were increased, particularly during the long time standing posture. Results indicate that body mass index (BMI) and gender were not significant factors in this study. Combination of sit/stand time duration 25/5 min appears to show positive effects on relief of muscle exposure of back of thigh in the shifts of sitting and standing work position. Med Pr 2017;68(3):315-327
\end{abstract}

Key words: electromyography, ergonomic intervention, perceived level of discomfort, root mean square, body mass index, gender differences

Corresponding author: Huining Pei, Northwestern Polytechnical University, Shaanxi Engineering Laboratory for Industrial Design, West Youyi Road 127, 710072 Xi’an, China, e-mail: peihuining@mail.nwpu.edu.cn

Received: August 30, 2016, accepted: January 20, 2017

\section{INTRODUCTION}

It has been proven that office workers spend, on average, about $45 \%$ of the job doing computer-based tasks and work is becoming more sedentary [1]. Roughly $50 \%$ of the U.S. working population is employed in tasks requiring significant time spent sitting [2]. Prolonged sitting has been linked to a number of health issues [3]. Great deals of practices were introduced, according to this problem, to reduce unbroken sitting time to improve health not only by individuals [4] as well as several organizations $[5,6]$. As a result, a number of sit-stand workstations have been developed to promote changes in working postures from seated to standing. The usage of sit-stand workstations seems to reduce the sitting time of office works at the workplace efficiently according to several studies $[7,8]$, and may have positive effects on workers' health.

However, long-term standing posture has been shown to be associated with many health risks and occupational disease, mainly focusing on lower extremity as well, such as lower extremity discomfort, fatigue, swelling and venous blood pooling [9]. Halim et al. [10] claimed that $4 \mathrm{~h}$ and 45 min of standing work (with a morning break of $15 \mathrm{~min}$ and a lunch break of $90 \mathrm{~min}$ ) was contributed to leg muscle fatigue among the production workers. 
Subjective discomfort in the lower extremity, such as pain in the lower leg and calf muscles, was investigated during prolonged standing and sitting [11]. Moreover, the study found that prolonged standing work during $2 \mathrm{~h}$ caused oedema formation in the feet [12]. Comparison of the perceived discomfort of level for lower extremity in sitting, standing, and sit/standing posture was established by Chester et al. [13], but there is a lack of objective data to measure physical exposure associated with sitstand stations (e.g., electromyography (EMG) data).

In addition, EMG is one of the reliable approaches that is used for quantifying muscle fatigue levels and physical exposure [14-16]. The musculoskeletal load was measured by several researchers associated with EMG for analyzing muscular response of upper limb [15-17], and for studying the muscle activities of lower limb $[18,19]$.

Some studies were associated with sit/stand posture in an ergonomic perspective mainly focused on the physical load of low back, shoulder and upper extremity $[8,20,21]$. Few, if any, studies proved data or evidence of quantification of lower extremity exposures. Moreover, previous studies lacked precision in the estimated ratio of sit and stand time period to reduce fatigue and exposure of lower extremity. To fill these gaps, this research quantitatively evaluated the influences of sit/stand time duration on muscular activation and perceived level of discomfort with the focus on lower extremity. Another objective of the study has been to examine various combinations of sit/stand time durations and related impact on musculoskeletal responses and user perceptions to help guide recommendations for sit-stand workstation usage.

\section{MATERIAL AND METHODS}

\section{Participants}

Twenty-five participants, including 12 males and $13 \mathrm{fe}$ males, participated in the study (Table 1). Participants were required to perform keyboard-typing and potential subjects had to have a typing speed of 50 words $/ \mathrm{min}$ measured in a 3 min standard typing test. None of the participants had ever worked as a professional typist, but all worked with a computer regularly. Sixty percent of the participants could type blindly. All participants were free of pain, numbness or tingling in the arms, neck, back and legs.

\section{Experimental design}

A repeated-measure design was used for testing the main effects of muscle activity (i.e., EMG measures) and perceived level of discomfort (PLD) in varied time durations by using a sit-stand workstation. Participants were asked to complete a typing task for $2 \mathrm{~h}$ during each of 5 days, and the 5 experimental days were separated by minimum $48 \mathrm{~h}$ in order to diminish the influence of muscle fatigue caused by previous trials. There were five 30 - $\mathrm{min}$ sit/stand combinations with 4 repetitive cycles: $5 / 25 \mathrm{~min}, 10 / 20 \mathrm{~min}, 15 / 15 \mathrm{~min}, 20 / 10 \mathrm{~min}$, and $25 / 5 \mathrm{~min}$. Exposure to these combinations was controlled using a balanced Latin square design [22].

\section{Independent variables}

Independent variables for this study included sit/stand time duration combinations (5 levels), muscle (8 levels), body part (10 levels), body mass index (BMI) (2 levels) and gender (2 levels). Combinations of sit/stand time duration are described under the experimental task section and included: 5/25 min (C1), 10/20 min (C2), $15 / 15 \mathrm{~min}$ (C3), 20/10 $\mathrm{min}$ (C4), and 25/5 min (C5). These combinations were estimated based on discussions of the acutal sit/stand time durations during the task of text entry. The electrodes were sited on the following muscles of the dominant extremity mainly focusing on lower body (Figure 1): rectus abdominis (RA), rectus femoris (RF), vastus lateralis (VL), vastus medialis (VM), semitendinosus (ST), biceps femoris (BF),

Table 1. Morphological data of respondents in the study of muscle activity and perceived discomfort in the lower extremity during various combinations of sit/stand time duration at a workstation

\begin{tabular}{|c|c|c|}
\hline \multirow{2}{*}{ Characteristics } & \multicolumn{2}{|c|}{$\begin{array}{l}\text { Respondents } \\
(\mathrm{M} \pm \mathrm{SD})\end{array}$} \\
\hline & $\begin{array}{l}\text { females } \\
(\mathrm{N}=13)\end{array}$ & $\begin{array}{c}\text { males } \\
(\mathrm{N}=12)\end{array}$ \\
\hline Age [years] & $20.8 \pm 2.2$ & $22.9 \pm 4.8$ \\
\hline Height $[\mathrm{cm}]$ & $164.1 \pm 7.1$ & $175.9 \pm 5.7$ \\
\hline Mass $[\mathrm{kg}]$ & $69.5 \pm 12.7$ & $68.3 \pm 11.4$ \\
\hline Body mass index (BMI) $\left[\mathrm{kg} / \mathrm{m}^{2}\right]$ & $26.0 \pm 5.9$ & $22.0 \pm 3.1$ \\
\hline
\end{tabular}




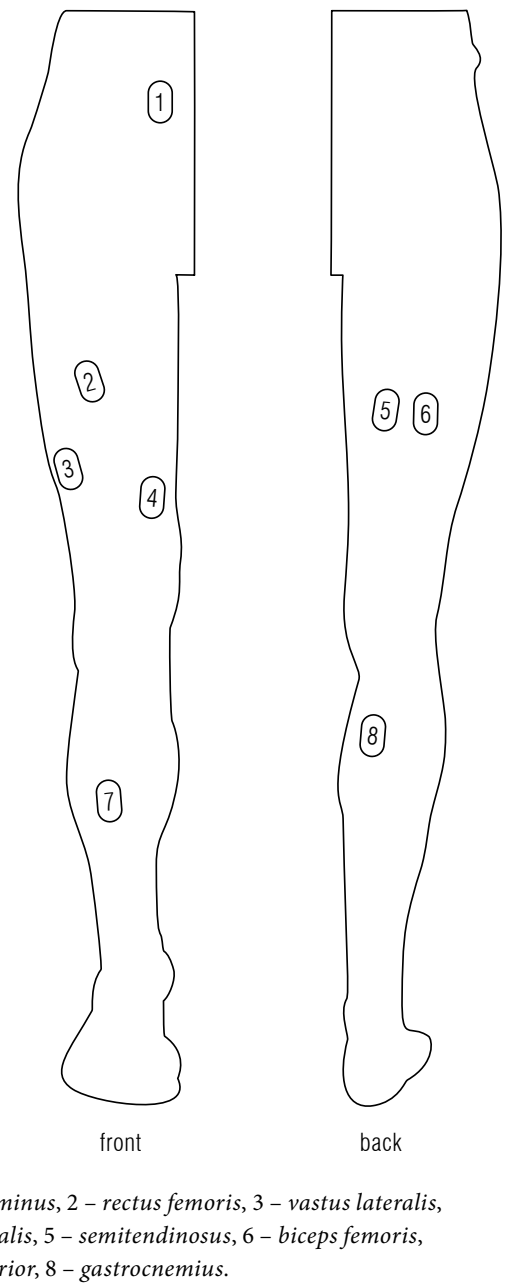

1 - rectus abdominus, 2 - rectus femoris, 3 - vastus laterali

4 - vastus medialis, 5 - semitendinosus,
7 -tibialis anterior, 8 - gastrocnemius.

Fig. 1. Position of the electrodes on the respondent's body

tibialis anterior (TA) and gastrocnemius (GC). Moreover, BMI was calculated by the formula body mass/ height ${ }^{2}$ and was taken into account to investigate the variation of EMG data and PLD values. According to the World Health Organization's (WHO) recommendations, BMI was categorized as underweight $\left(<18.5 \mathrm{~kg} / \mathrm{m}^{2}\right)$, normal $\left(18.5-24.99 \mathrm{~kg} / \mathrm{m}^{2}\right)$, and overweight $\left(25-29.99 \mathrm{~kg} / \mathrm{m}^{2}\right)$. Given only one underweight participant, the underweight and normal categories were combined.

\section{Dependent variables}

The dependent variables were muscle activation, and perceived level of discomfort (PLD).

\section{Electromyography measurements}

Surface EMG was quantified for the lower abdomen and lower limb muscles of the dominant side. Rectangular $\mathrm{Ag} / \mathrm{AgCl}$ pre-gelled bipolar disposable elec- trodes were attached using standard preparation and placement procedures [23]. Myosystem 1400A (Noraxon, USA) was used for recording the measurements and processing the EMG signals amplified, band-pass filtered $(10-500 \mathrm{~Hz})$, acquired at a sampling frequency of $1 \mathrm{kHz}$. Following a 15-min stabilization period, impedance was measured to ensure that it was below $10 \mathrm{k} \Omega$ (otherwise, the electrode site was re-prepared and electrodes reattached). Since EMG data was investigated across 5 different days, electrode locations were marked using a permanent marker pen to make sure that the electrode locations were relocated in the same area.

Resting EMG and sub-maximal voluntary contractions (SMVCs) were performed and recorded to normalize the EMG signal. Resting EMG signals were sampled at $5 \mathrm{~Hz}$ for $5 \mathrm{~s}$ and recorded with the participant standing in a relaxed posture [24]. A $5 \mathrm{~s}$ rampup and ramp-down procedure was used for collecting the SMVCs. The ramp-up and ramp-down procedure had required subjects to steadily increase the abduction force in certain reference positions over a $2 \mathrm{~s}$ verbal count up to their sub-maximum voluntary force, then the abduction force had been sustained at this force for about $1 \mathrm{~s}$ before it was gradually reduced over a $2 \mathrm{~s}$ count back to loosen muscle. For RA, the participant lay on the floor with arms resting at body side and legs lifted up at $30^{\circ}$ [25]. For RF, VL, VM and TA the participant was half-squatting on the ground with arms and legs bending at $90^{\circ}$ [26]. For ST and BF, the participant was touching a wall with hands at dominant leg flexing backwards at $10^{\circ}$. For GC, the participant was standing straight on the ground with toes raising at $60^{\circ}$ [27]. A minimum of 3 SMVCs will be collected for each muscle. If the final SMVC measures result in the peak muscle activation recorded, additional SMVCs will be collected until maximum is not observed. And the peak value recorded for each muscle was used for normalization purposes.

\section{Perceived level of discomfort}

Perceived level of discomfort was assessed using a modified Borg's perceived level of exertion scale [28], the scores of which are presented in the Table 2. Participants were asked to verbally provide the score of PLD for the parts of abdomen (ABD), hips (HIP), left front of thigh (LFT), left back of thigh (LBT), right front of thigh (RFT), right back of thigh (RBT), left front of calf (LFC), left back of calf (LBC), right front of calf (RFC), right back of calf (RBC) before and after every testing. 
Table 2. Perceived level of discomfort (PLD) scale [28]

\begin{tabular}{ll}
\hline $\begin{array}{r}\text { Scale } \\
\text { [pts] }\end{array}$ & \multicolumn{1}{c}{ Description } \\
\hline 0 & not noticeable discomfort \\
0.5 & very, very light discomfort (just noticeable) \\
1 & very light discomfort \\
2 & light discomfort \\
3 & moderate discomfort \\
4 & somewhat high discomfort \\
$5-6$ & high discomfort \\
$7-9$ & very high discomfort \\
10 & very, very high discomfort \\
\hline
\end{tabular}

\section{Experimental task}

The experimental task consisted of 5-day task simulations by using a sit-stand workstation, which is an articulated arm that attaches to the back or side of a regular desk/a stand that attaches to the front of a regular desk that raises or lowers by pulling the handle in the front (manual adjustment) and has a work surface to place a keyboard, mouse and/or docking station, typing text according a specific book in scanned version (Photo 1). The five testing sessions (for each of the sit/ stand time duration combinations) lasting $2 \mathrm{~h} \mathrm{[29]} \mathrm{and}$ separated by a minimum of $48 \mathrm{~h}$ and five 30 -min sit/ stand combinations were studied. All test sessions were completed at approximately the same time of a day. Participants were equipped with data collection equipment, which allowed to practice using the sit-stand workstation, complete baseline data collection procedures.

\section{Procedures}

Participants received a written and verbal description of the study and its objectives, and completed informed consent documents approved by the Mississippi State University's Institutional Review Board (IRB) prior to data collection. Participants also completed a demographic questionnaire for determining participant eligibility. Data collection equipment was attached, participants rested for $10 \mathrm{~min}$. Impedance was assessed, and SMVC trials were completed. Prior to commencement of the tasks, participants were briefed about the tasks and completed a 1-min familiarization session on the use of the sit-stand workstation. The familiarization period was followed by a 5 -min rest period and the test session. All participants completed a single 2 -h test session and finished with the completion a)

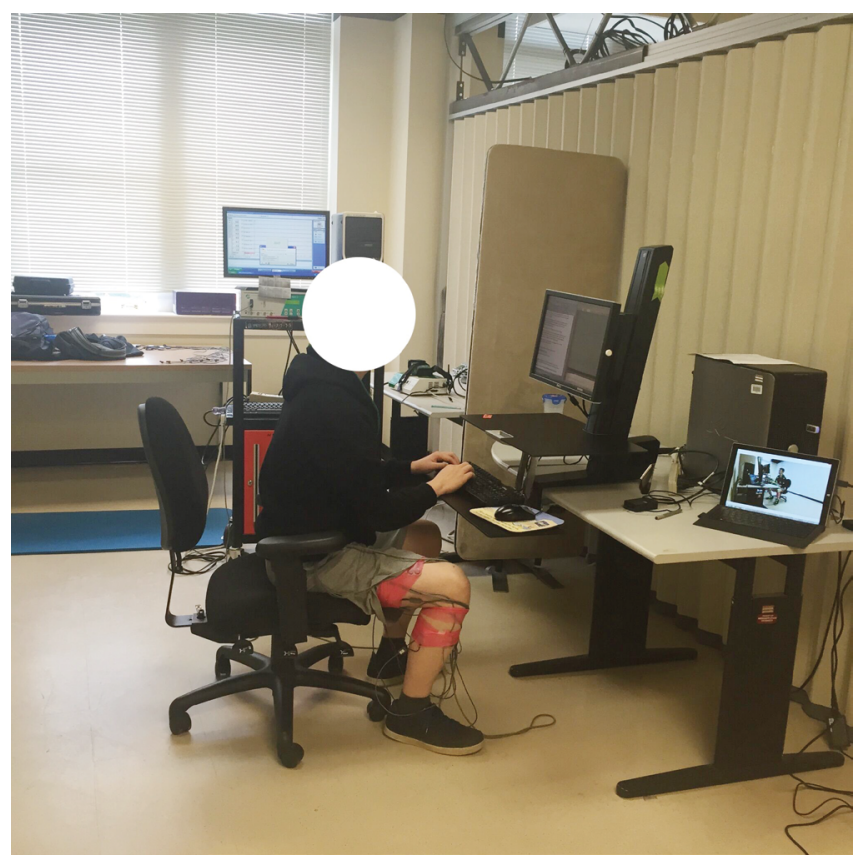

b)

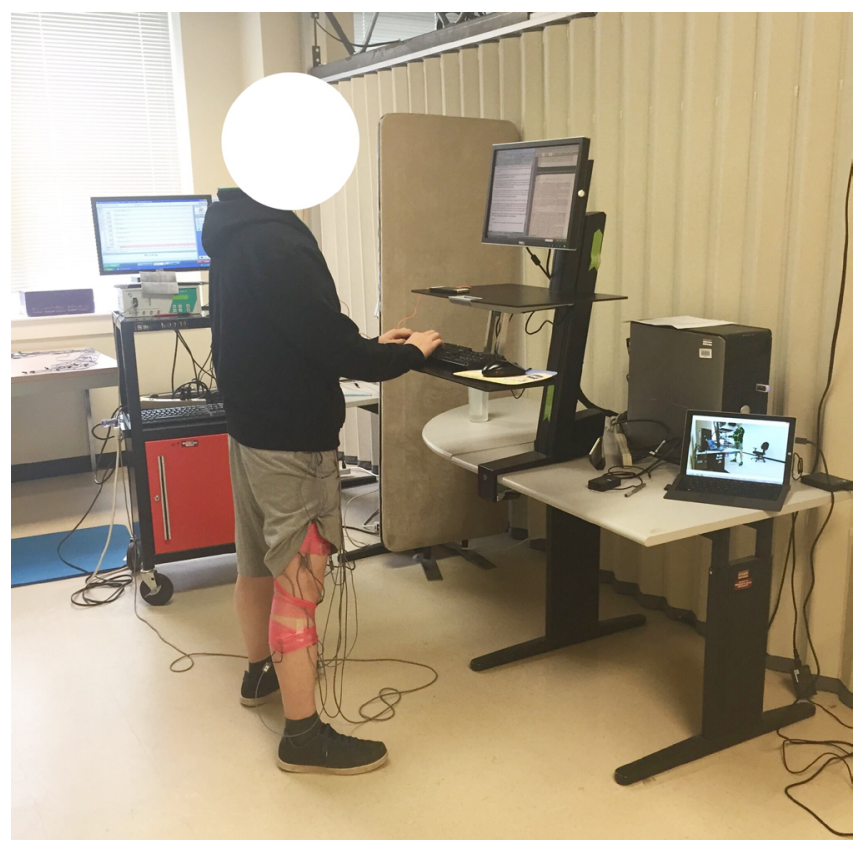

Photo 1. Text entry task at a) sit and b) stand workstation

of a questionnaire of perceived level of discomfort. At the end of the session, participants were monetarily compensated.

\section{Data analysis}

Descriptive statistics were evaluated for each dependent variable. The experimental data showed that the PLD values satisfied the homogeneity of variance 
Table 3. Descriptive statistics for the dependent variables by combinations of sit/stand time duration at a workstation

\begin{tabular}{|c|c|c|c|c|c|}
\hline Dependent variable & \multicolumn{5}{|c|}{ Sit/stand time duration } \\
\hline rectus abdominus (RA) & $1.93 \pm 0.72$ & $1.97 \pm 0.70$ & $2.15 \pm 0.89$ & $2.21 \pm 1.24$ & $2.25 \pm 0.88$ \\
\hline rectus femoris (RF) & $1.66 \pm 0.42$ & $1.68 \pm 0.58$ & $1.81 \pm 0.64$ & $1.53 \pm 0.46$ & $1.46 \pm 0.22$ \\
\hline vastus medialis (VM) & $1.34 \pm 0.30$ & $1.44 \pm 0.45$ & $1.71 \pm 0.64$ & $1.36 \pm 0.31$ & $1.29 \pm 0.24$ \\
\hline semitendinosus (ST) & $1.90 \pm 0.57$ & $1.98 \pm 0.61$ & $2.34 \pm 1.30$ & $1.66 \pm 0.24$ & $1.46 \pm 0.21$ \\
\hline biceps femoris $(\mathrm{BF})$ & $2.19 \pm 0.71$ & $2.26 \pm 0.85$ & $2.15 \pm 0.82$ & $1.73 \pm 0.51$ & $1.49 \pm 0.25$ \\
\hline tibialis anterior (TA) & $3.06 \pm 1.26$ & $2.51 \pm 1.30$ & $2.80 \pm 1.49$ & $3.04 \pm 1.64$ & $2.38 \pm 1.29$ \\
\hline \multicolumn{6}{|c|}{$\begin{array}{l}\text { Perceived level of discomfort [pts] } \\
(\mathrm{M} \pm \mathrm{SD})\end{array}$} \\
\hline abdomen (ABD) & $0.72 \pm 1.20$ & $0.48 \pm 1.12$ & $0.64 \pm 1.35$ & $0.24 \pm .59$ & $0.48 \pm 1.29$ \\
\hline hips (HIP) & $1.36 \pm 1.89$ & $1.00 \pm 1.60$ & $1.04 \pm 1.92$ & $0.76 \pm 1.53$ & $0.64 \pm 1.72$ \\
\hline left front of thigh (LFT) & $1.76 \pm 2.06$ & $1.04 \pm 1.54$ & $0.92 \pm 1.63$ & $0.60 \pm 1.22$ & $0.56 \pm 1.38$ \\
\hline left back of thigh (LBT) & $1.44 \pm 1.89$ & $1.44 \pm 2.10$ & $1.48 \pm 1.80$ & $0.88 \pm 1.71$ & $0.76 \pm 1.36$ \\
\hline right front of thigh (RFT) & $1.92 \pm 2.13$ & $1.40 \pm 1.73$ & $1.36 \pm 1.91$ & $0.80 \pm 1.19$ & $0.80 \pm 1.63$ \\
\hline right back of thigh (RBT) & $1.52 \pm 1.96$ & $1.56 \pm 1.98$ & $1.64 \pm 1.72$ & $0.84 \pm 1.70$ & $0.80 \pm 1.32$ \\
\hline left front of calf (LFC) & $1.80 \pm 2.12$ & $1.72 \pm 2.18$ & $1.20 \pm 1.93$ & $0.80 \pm 1.78$ & $0.64 \pm 1.25$ \\
\hline left back of calf (LBC) & $2.72 \pm 2.45$ & $2.44 \pm 2.43$ & $2.40 \pm 2.67$ & $1.52 \pm 2.14$ & $0.72 \pm 1.45$ \\
\hline
\end{tabular}

Abbreviations as in Table 3.

assumption and the normality assumption of the oneway analyses of variance (ANOVAs), but the muscle activities values did not. Nonparametric tests were employed to analyze the mean EMG.

The 1-way analysis of variance (ANOVAs) was carried out to test for effects of sit/stand time duration combinations, BMI and gender on the PLD values for 10 body parts. Tukey tests were used in post hoc comparisons where appropriate.

Kruskal-Wallis 1-way analysis of variance was utilized to determine significant differences for the 8 muscles' mean EMG in the various combinations of sit/ stand time duration. The differences in changes in muscle activities among 5 sit/stand time duration groups were compared with Wilcoxon's rank sum test (MannWhitney $\mathrm{U}$ test). Line plot has been calculated as well as the mean of PLD for lower extremity across different groups was tested.

Spearman's correction was used for explaining the repeatability of each dependent variable. The analysis was completed using SPSS (IBM SPSS Statistics, v. 20) and all results were considered significant at a level of 0.05 .

\section{RESULTS}

\section{Electromyography data}

Descriptive statistics for the dependent variables were presented in the Table 3. Sit/stand time durations C5 required less muscle activity than any other combinations of sit/stand time durations and the mean EMG value of TA and GC was relatively higher than any other 6 muscles.

The ANOVA results showed that the mean EMG was affected by combinations of sit/stand time durations (Table 4) and ST and BF muscle activity differed significantly $(\mathrm{r}=17.974, \mathrm{p}=0.01 ; \mathrm{r}=16.368, \mathrm{p}=0.03)$. The Table 5 showed that, in general, significant differences for the muscle activation of ST and BF were found across the sit/stand time durations $\mathrm{C} 5$, among others 
Table 4. One-way ANOVA between the dependent variables across combinations of sit/stand time duration at a workstation

\begin{tabular}{|c|c|c|c|c|}
\hline Variable & \multicolumn{2}{|c|}{ Nonparametric one-way ANOVA Kruskal-Wallis } & \multicolumn{2}{|c|}{ Parametric one-way ANOVA } \\
\hline \multicolumn{5}{|l|}{ Electromyography $(\mathrm{M})$} \\
\hline rectus abdominus (RA) & 1.234 & 0.873 & & \\
\hline rectus femoris $(\mathrm{RF})$ & 3.401 & 0.493 & & \\
\hline semitendinosus (ST) & 17.974 & 0.001 & & \\
\hline biceps femoris $(\mathrm{BF})$ & 16.368 & 0.003 & & \\
\hline tibialis anterior $(\mathrm{TA})$ & 5.895 & 0.207 & & \\
\hline hips (HIP) & & & 0.638 & 0.637 \\
\hline left front of thigh (LFT) & & & 2.299 & 0.063 \\
\hline left back of thigh (LBT) & & & 0.952 & 0.437 \\
\hline right front of thigh (RFT) & & & 1.812 & 0.131 \\
\hline right back of thigh (RBT) & & & 1.399 & 0.238 \\
\hline left front of calf (LFC) & & & 1.931 & 0.110 \\
\hline left back of calf (LBC) & & & 3.303 & 0.013 \\
\hline right front of calf (RFC) & & & 1.840 & 0.126 \\
\hline
\end{tabular}

M-mean.

Bolded values indicate significant differences $(\mathrm{p}<0.05)$

for ST - C1 vs. C5 ( $\mathrm{p}=0.006), \mathrm{C} 2$ vs. C5 ( $\mathrm{p}=0.002)$, C3 vs. C5 ( $p=0.002)$, C4 vs. C5 ( $\mathrm{p}=0.003)$; for BF C1 vs. C5 ( $\mathrm{p}=0.000), \mathrm{C} 2$ vs. C5 ( $\mathrm{p}=0.012), \mathrm{C} 3$ vs. C5 $(\mathrm{p}=0.002)$.

In addition, the muscle activation of $\mathrm{VM}$ also differed significantly for 3 group comparisons: $\mathrm{C} 1$ vs. $\mathrm{C} 3$ ( $\mathrm{p}=0.044), \mathrm{C} 3$ vs. $\mathrm{C} 4$ ( $\mathrm{p}=0.036), \mathrm{C} 3$ vs. C5 $(\mathrm{p}=0.036)$.

Mann-Whitney $U$ test was utilized to determine effects of BMI and gender on EMG values. No significant differences ( $p>0.05$ for all of 8 muscles) for muscle activation among BMI groups (normal vs. overweight) were identified.

Likewise, there was no significant difference for muscle activation between genders. Among them, EMG of overweight subjects ranked higher than in the case of standard subjects (mean rank, overweight vs. normal): RF (8.50 vs. 7.67$)$, VL (8.67 vs. 7.00$)$, VM (8.83 vs. 7.44$)$, ST (9.17 vs. 7.22$)$, BF (8.00 vs. 8.00$)$, TA (8.56 vs. 7.17$)$, and GC (9.17 vs. 7.22).

\section{Perceived level of discomfort}

The Table 4 showed that the perceived level of discomfort values of $\mathrm{LBC}$ and $\mathrm{RBC}$ different significantly $(\mathrm{r}=3.303, \mathrm{p}=0.13 ; \mathrm{r}=2.584, \mathrm{p}=0.40)$. The results of Tukey in terms of HSD (honestly significant difference) presented that significant difference for the discomfort ratings of $\mathrm{LBC}$ was found across $\mathrm{C} 1$ between $\mathrm{C} 5$ $(\mathrm{p}=0.19)$ and no significant difference was found among the other 6 groups (Figure 2, Table 5). Moreover, in general, the mean PLD values of C5 was significantly lower than any other combinations (Table 3, Figure 3).

No statistically significant differences for PLD values between standard subjects and overweight subjects $(p>0.05)$ and between male subjects and female subjects ( $p>0.05$ ) were identified. In general, female subjects had higher discomfort rating than male on the region of calf and back thigh: LBT (female: $1.50 \pm 2.00$, male: $1.31 \pm 1.43$ ), RBT (female: $1.50 \pm 2.07$, male: $1.46 \pm$ 1.51), LFC (female: $1.83 \pm 2.62$, male: $1.46 \pm 2.025$ ), RFC 


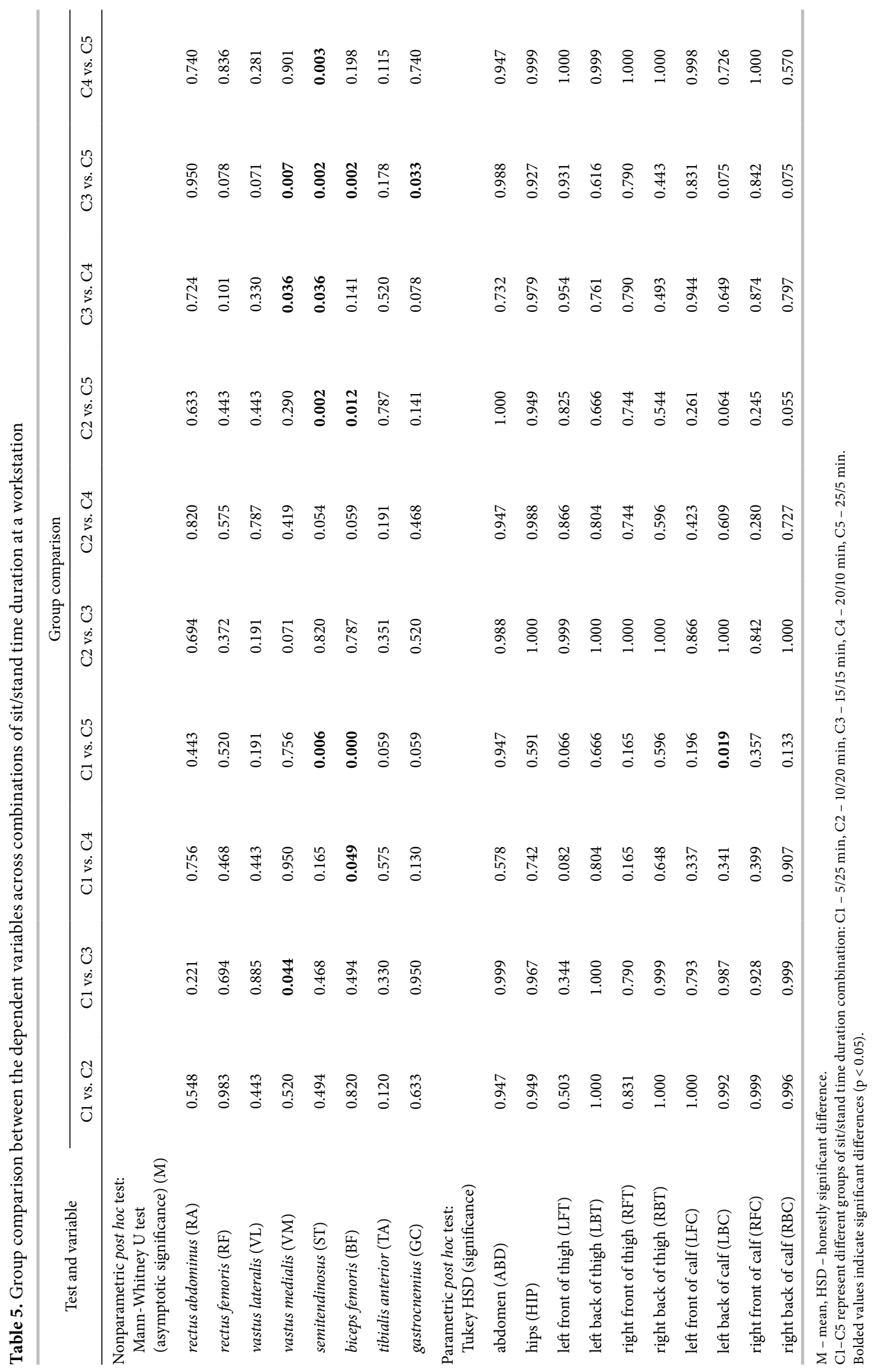




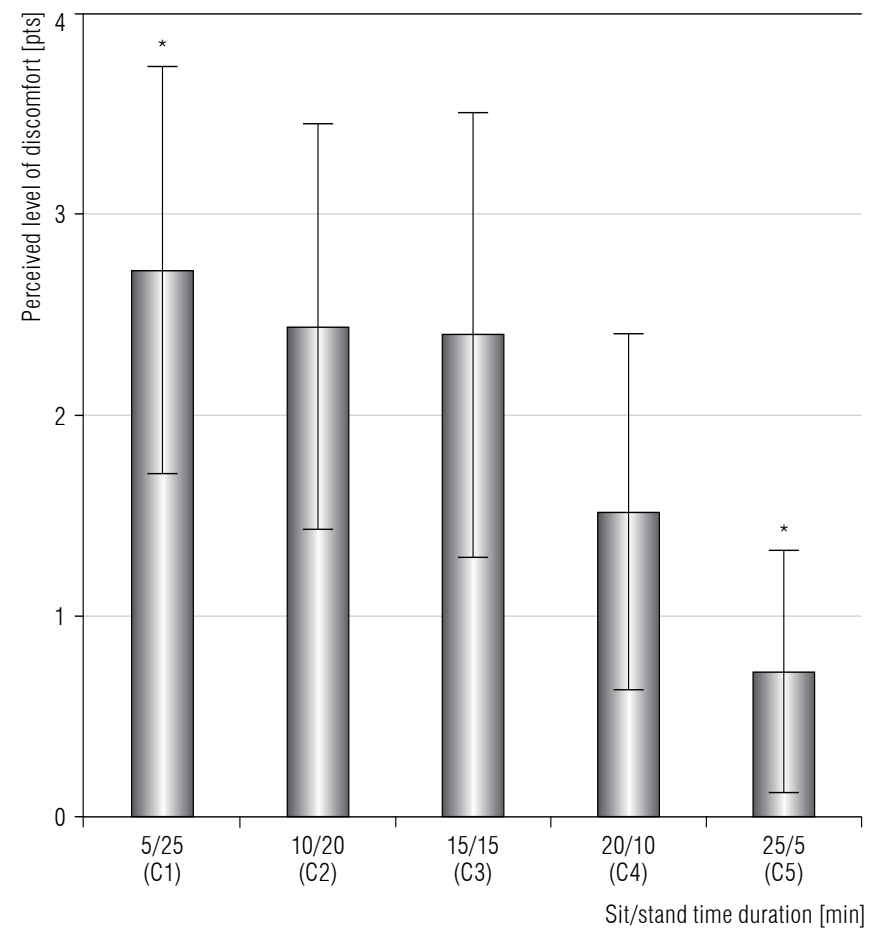

Abbreviations as in Table 3.

* Significant difference.

Fig. 2. Mean perceived level of discomfort (PLD) for left back of calf (LBC) across combinations of sit/stand time duration at a workstation

(female: $2.17 \pm 2.66$, male: $1.69 \pm 1.75$ ), RBC (female: $2.17 \pm 2.66$, male: $1.69 \pm 1.75$ ).

\section{Repeatability}

Linear correlations were computed to assess repeatability across combinations of sit/stand time duration (Table 6). All nonparametric correlations had Spearman's rho above -0.148 except for the mean EMG of ST, BF, GC (Figure 4), which had correlation coefficient of $-0.389,-0.445,-0.252$, respectively. Apart from the mean of RFT, RBT values, Pearson's correlations were above -0.159 , indicating a weak correlation between sit/stand time durations. Out of the correlations, $78 \%$ were weak ( $\mathrm{p}>0.05$ ), $16 \%$ were moderate $(0.05 \leq \mathrm{p}<0.01)$ and $6 \%$ were strong $(\mathrm{p} \leq 0.01)$.

\section{DISCUSSION}

Utilizing sit-stand workstations is one of the interventions that has been proven having positive impact on the health of office workers. Most of the pervious research mainly focused on the muscle exposures of upper limb, shoulder, neck and lower back using sit-stand workstations. However, few studies examined the physi-

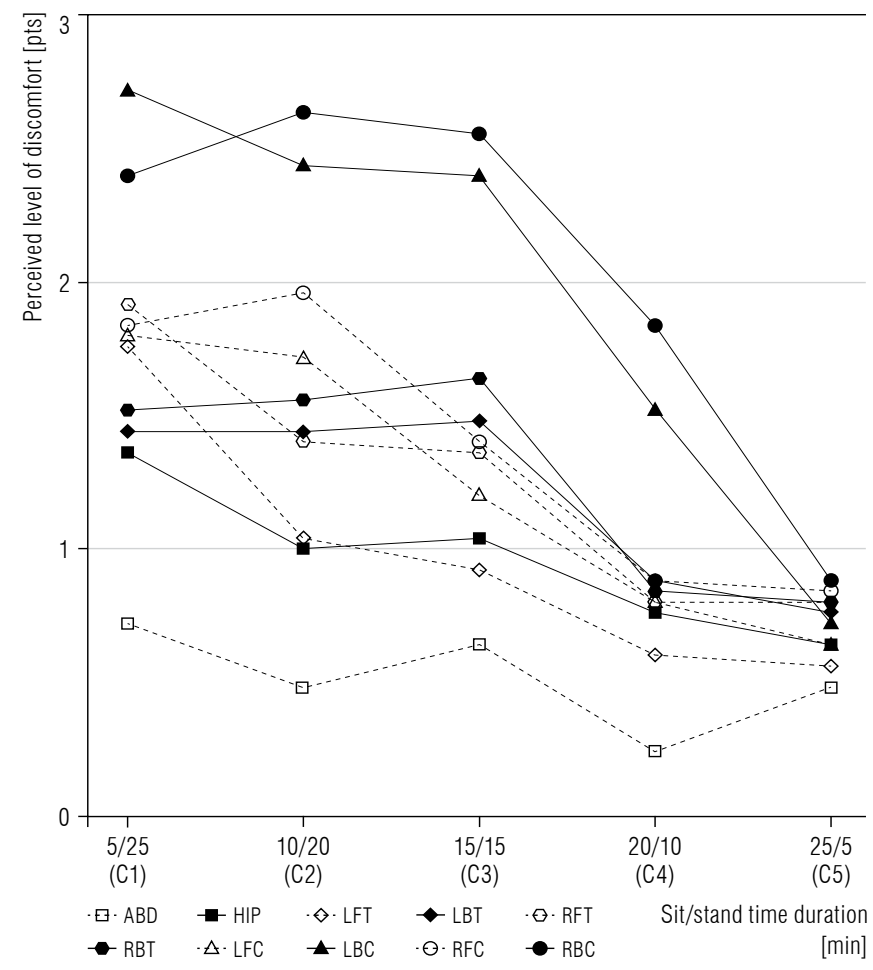

Abbreviations as in Table 3.

Fig. 3. Mean perceived level of discomfort (PLD) across combinations of sit/stand time duration at a workstation by body part

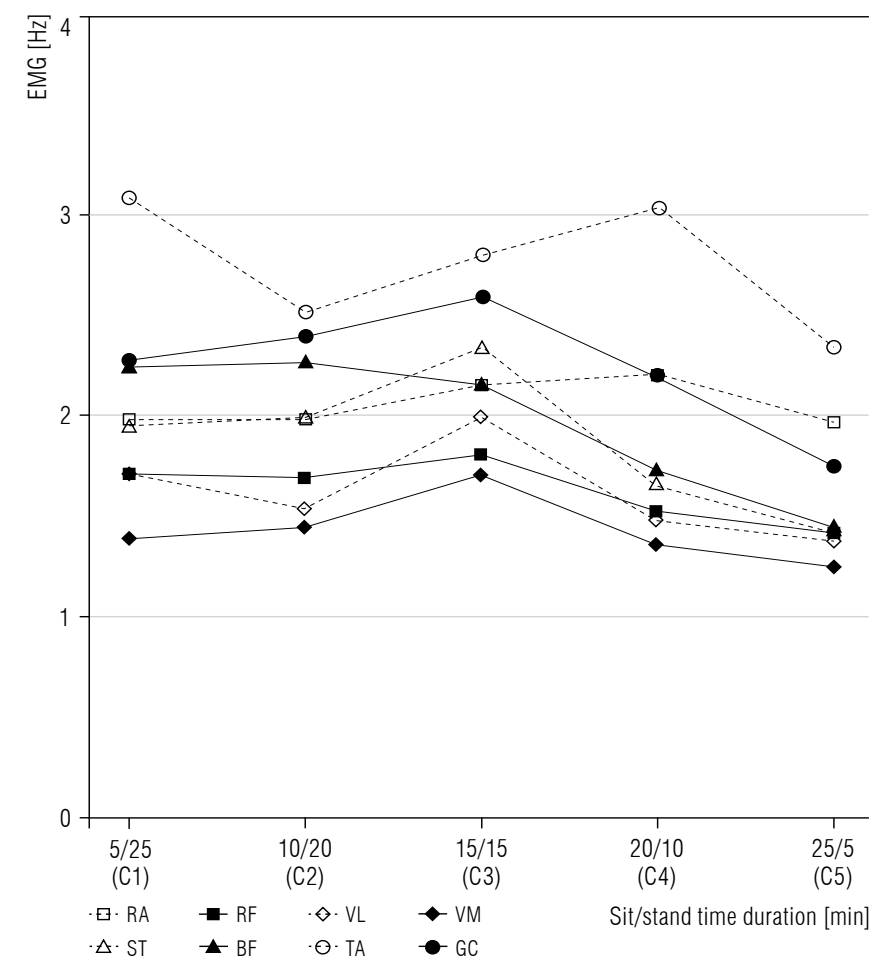

Abbreviations as in Table 3.

Fig. 4. Mean electromyography (EMG) across combinations of sit/stand time duration at a workstation 
Table 6. Spearman's correlation coefficients for the variables across combinations of sit/stand time duration at a workstation

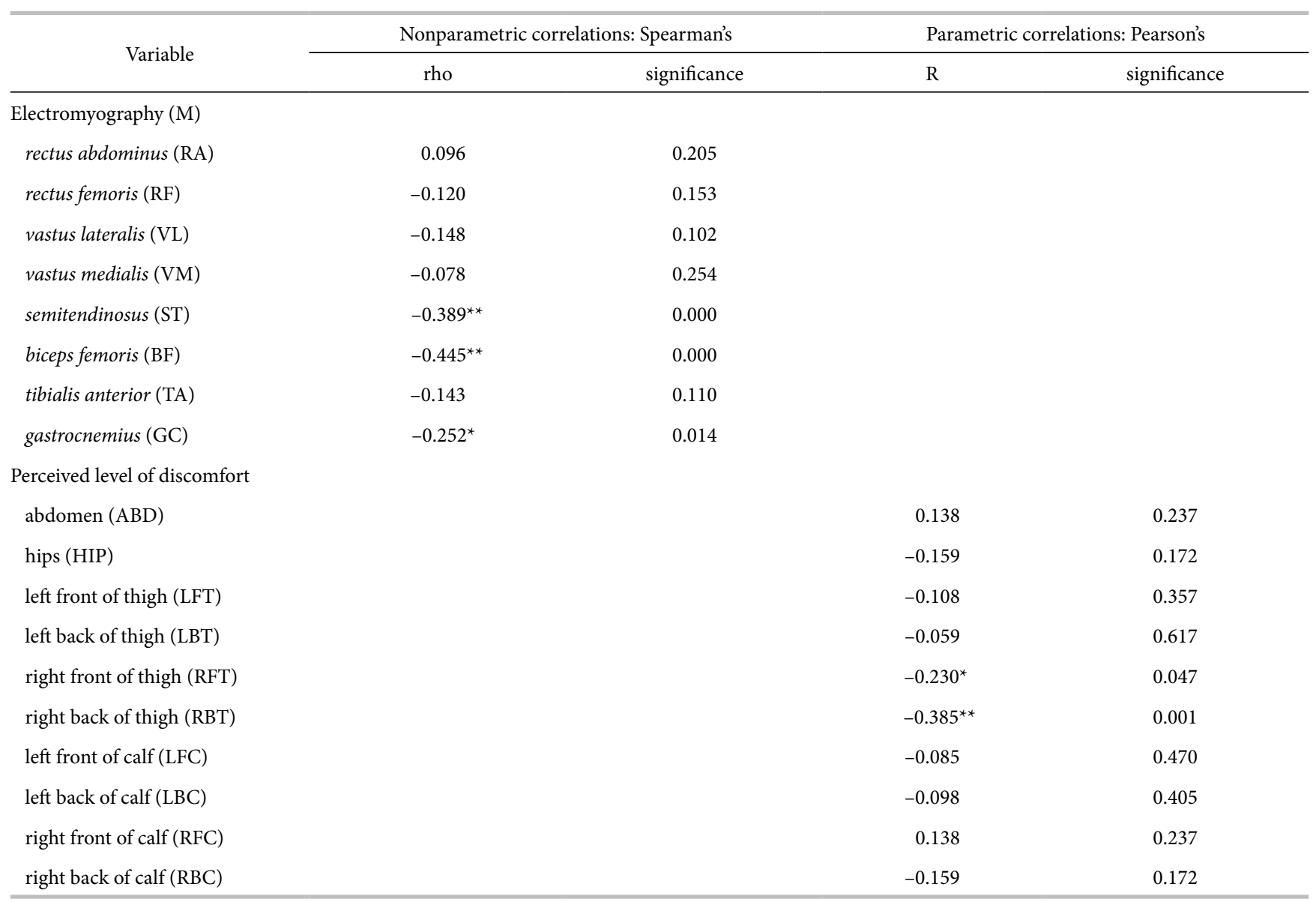

$\mathrm{M}$ - mean, rho - Spearman's rank correlation coefficient.

** Significant at 0.01 level.

* Significant at 0.05 level.

cal load of lower extremity while using the sit-stand office workstation. Besides, many health problems of lower extremity for standing work posture were reported as well. Thus, this study investigated the impact of the 5 different combinations of sit/stand time durations on lower extremity muscle activity and perceived level of discomfort while using a sit-stand workstation.

This study demonstrated the lower leg muscles (TA, GC) activities at a high rate in the standing posture, which was consistent with the finding of $\mathrm{Ba}-$ lasubramanian et al. [30] (Figure 4). In addition, the Figure 3 presented a low level of perceived discomfort for C5 and the mean PLD value increased with the longer standing time. Muscle fatigue was regarded as a factor in the development of body health issues, such as muscle pain, joint disorder and soft tissue injuries [31-33] and Lin et al. [34] claimed that leg movement influenced perceived discomfort of the shank significantly. Thus, this analysis agreed with the previous research that lower limb muscular discomfort existed while standing [35] and standing was less comfortable as compared with sitting [13]. Moreover, the Table 4 reported that the mean values of $\mathrm{LBC}$ and $\mathrm{RBC}$ (the segment region of calf) differed significantly across the combinations of sit/stand time duration, these results being consistent with the opinion of Chester et al. [13]. But no significant muscle exposure differences were found among these segment regions. The lack of correlation between EMG and perceived discomfort was possibly a consequence of the poor measurement repeatability [36].

According to the Table 4, this study showed that the mean EMG of semitendinosus (ST) and biceps femoris $(\mathrm{BF})$ was affected by combinations of sit/stand time duration significantly. According to Gray [37], those two muscles belong to the thigh of lower extremity segment region, therefore, the muscle exposure of the back of thigh is noticeably influenced by sit/stand time duration. However, no significant perceived discomfort differences were found among these segment regions. 
Further data analysis of group comparison between the combinations of sit/stand time duration illustrated that significant differences for the muscle activation of ST and BF were found among C5 and the other 4 sit/ stand time duration groups (Table 5). Besides, the Table 3 and Figure 2 showed that there was lower muscular activation on all eight muscles and lower mean perceived discomfort value on all ten body parts under the condition of C5. Increasing RMS value with an advancing fatigue was reported [38]. And pervious research proved that higher muscle activity levels may have been due to localized muscle fatigue and more physical exposure [39].

Therefore, this study identifies that combinations of sit/stand time duration 25/5 min (C5) result in less lower extremity muscle exposure, especially for the thigh of lower extremity region with significant difference in ST and BF and most of group comparisons among C5 and others (Table 4, Table 5) while using sitstand workstation to perform $2 \mathrm{~h}$ text entry task. The Figure 4 showed that C5 resulted in lower PLD values although no significant difference was found for most of body parts. It is worth noting that the combinations of sit/stand time duration $30 / 0 \mathrm{~min}$ and $0 / 30 \mathrm{~min}$ were not taken into account because those conditions meant prolonged sitting and prolonged standing, respectively, and could not estimate the relationship of the shifts of sit-stand position. In addition, the muscle activation of VM also differed significantly for 3 group comparisons (Table 5). This result illustrated that the muscle exposure of the front of thigh was influenced by sit/stand time duration significantly.

In this study, although mean EMG of overweight subjects was ranked higher than for standard subjects, there was no significant effect of BMI on muscle activation using sit-stand workstation over 2-h typing tasks. To the best of our knowledge, fewer studies reported the relationship between BMI and EMG signal variations. Indeed, BMI was associated with increased prevalence of work-related musculoskeletal disorders (WMSDs) and increased scores of musculoskeletal discomfort $[40,41]$. It may be necessary to investigate the longer term effects of BMI on muscle activation in future work since BMI influences chronic musculoskeletal pain/discomfort in a roundabout way [42].

No significant gender difference was found, and results from males and females were pooled for this study. Likewise, gender did not result in any significant discrimination in explaining discomfort responses during 2-h sitting on vehicle seats and in reporting [43] and in reporting EMG activities of upper extremity during 1-h computer work [44]. However, it should be noted that higher discomfort rating was found among female subjects. In this sense, it seems that female computer users are more often exposed to physical risk factors as compared with males $[45,46]$.

Woods and Babski-Reeves [47] reported that there was no prior research that had addressed repeatability of data entry regarding physical load variables because it was difficult to locate electrodes to identify the related placement across test sessions and participants. This result matches with this research with $78 \%$ weak correlation ( $p>0.05)$ for EMG and PLD data across five combinations of sit/stand time duration (Table 6).

There are several limitations of this study that should be presented. First of all, only muscular activation of the lower extremity was examined. Additional consideration to muscular activation of hip and buttock would be taken to investigate that how sit/stand time duration affects the lower body as a whole. Furthermore, the small sample size may limit the generalization of results, and the trial needs to be repeated using a larger sample consequently. Finally, the data of posture shift or the change of joint angle were not collected. There are several studies showing that the change of posture or joint angle is effective data to analyze the physical exposure and use electrogoniometers or kinect camera to quantify the load of physical body parts $[48,49]$.

\section{CONCLUSIONS}

This study has sought to identify the lower extremity exposures in various combinations of sit/stand time durations associated with a sit-stand workstation. Ergonomic exposures of lower extremity when using a sitstand workstation were increased, particularly during the long time standing posture. The muscle activity of the thigh region was influenced by sit/stand time duration significantly. The objective and subjective measure showed inconsistent results. The lack of correlation between subjective and objective estimation was possibly due to the poor measurement repeatability. Significant physiological (muscle activity) differences were found among C5 and the other 4 combinations of sit/stand duration, especially for the muscle of $s e$ mitendinosus (ST), biceps femoris (BF), by using a sitstand workstation. Thereby, combination of sit/stand time duration $25 / 5 \mathrm{~min}$ appears to show positive effects on relief of muscle exposure of back of thigh in the shifts of sitting and standing work position. More- 
over, BMI and gender were not significant factors in this study. Future studies should include other sit/stand time durations and longer period (such as a whole workday period) should be tested to determine the effects of sit/stand time durations on physical exposures.

\section{ACKNOWLEDGMENTS}

The authors would like to acknowledge the support of students and staffs of the Human Systems Engineering Laboratory of the Mississippi State University for their assistance in data collection and analysis. The authors would especially like to thank Dr. Kari Babski-Reeves for her help with the experiment design, implementation and financial support.

\section{REFERENCES}

1. Barbieri DF, Srinivasan D, Mathiassen SE, Nogueira HC, Oliveira $\mathrm{AB}$. The ability of non-computer tasks to increase biomechanical exposure variability in computer-intensive office work. Ergonomics. 2015;58(1):50-64, https://doi. org/10.1080/00140139.2014.965753.

2. Strawderman L, Thomas LR, Reeves KB, Greenwood A. Investigating the impact of process complexity on quality of care in hospital emergency departments. Int J Healthc Technol Manage. 2013;14(1/2):22-38, https://doi.org/10.1504/ IJHTM.2013.055082.

3. Biswas A, Oh PI, Faulkner GE, Bajaj RR, Silver MA, Mitchell MS, et al. Sedentary time and its association with risk for disease incidence, mortality, and hospitalization in adults: A systematic review and meta-analysis. Ann Intern Med. 2015;162(2):123-32, https://doi.org/10.7326/ M14-1651.

4. Van Uffelen JGZ, Wong J, Chau JY, van der Ploeg HP, Riphagen I, Gilson ND, et al. Occupational sitting and health risks: A systematic review. Am J Prev Med. 2010;39 (4):379-88, https://doi.org/10.1016/j.amepre.2010.05.024.

5. Department of Health and Human Services, Centers for Disease Control and Prevention, National Institute for Occupational Safety and Health. Essential elements of effective work-place programs and policies for improving worker health and wellbeing. Washington: The Institute; 2008.

6. World Health Organization [Internet]. Geneva: The Organization; 2017 [cited 2016 Aug 1]. Healthy workplaces: A model for action: For employers, workers, policy-makers and practitioners. Available from: http://apps.who.int/iris/ handle/10665/44307.

7. Alkhajah TA, Reeves MM, Eakin EG, Winkler EAH, Owen N, Healy GN. Sit-stand workstations: A pilot interven- tion to reduce office sitting time. Am J Prev Med. 2012;43 (3):298-303, https://doi.org/10.1016/j.amepre.2012.05.027. 8. Straker L, Abbott RA, Heiden M, Mathiassen SE, Toomingas A. Sit-stand desks in call centres: Associations of use and ergonomics awareness with sedentary behavior. Appl Ergon. 2013;44(4):517-22, https://doi.org/10.1016/j.apergo.2012.11.001.

9. Sudoł-Szopińska I, Bogdan A, Szopiński T, Panorska AK, Kołodziejczak M. Prevalence of chronic venous disorders among employees working in prolonged sitting and standing postures. Int J Occup Saf Ergon. 2011;17(2):165-73, https://doi.org/10.1080/10803548.2011.11076887.

10. Halim I, Omar AR, Saman AM, Othman I. Assessment of muscle fatigue associated with prolonged standing in the workplace. Saf Health Work. 2012;3(1):31-42, https://doi. org/10.5491/SHAW.2012.3.1.31.

11. Messing K, Kilbom Å. Standing and very slow walking: Foot pain-pressure threshold, subjective pain experience and work activity. Appl Ergon. 2001;32(1):81-90, https:// doi.org/10.1016/S0003-6870(00)00030-2.

12. Hansen L, Winkel J, Jørgensen K. Significance of mat and shoe softness during prolonged work in upright position: Based on measurements of low back muscle EMG, foot volume changes, discomfort and ground force reactions. Appl Ergon. 1998;29(3):217-24, https://doi.org/10.1016/S00036870(97)00062-8.

13. Chester MR, Rys MJ, Konz SA. Leg swelling, comfort and fatigue when sitting, standing, and sit/standing. Int J Ind Ergon. 2002;29(5):289-96, https://doi.org/10.1016/S016 9-8141(01)00069-5.

14. Silva L, Vaz JR, Castro MA, Serranho P, Cabri J, PezaratCorreia P. Recurrence quantification analysis and support vector machines for golf handicap and low back pain EMG classification. J Electromyogr Kinesiol. 2015;25(4):637-47, https://doi.org/10.1016/j.jelekin.2015.04.008.

15. Ellegast RP, Kraft K, Groenesteijn L, Krause F, Berger H, Vink P. Comparison of four specific dynamic office chairs with a conventional office chair: Impact upon muscle activation, physical activity and posture. Appl Ergon. 2012;43(2):296-307, https://doi.org/10.1016/j.apergo. 2011.06.005.

16. Gowland C, DeBruin H, Basmajian JV, Plews N, Burcea I. Agonist and antagonist activity during voluntary upper-limb movement in patients with stroke. Phys Ther. 1992 Sep;72(9):624-33, http://ptjournal.apta.org/content/ $72 / 9 / 624$.

17. Rade M, Shacklock M, Peharec S, Bačić P, Candian C, Kankaanpää $M$, et al. Effect of cervical spine position on upper limb myoelectric activity during pre-manipulative stretch for Mills manipulation: A new model, relations 
to peripheral nerve biomechanics and specificity of Mills manipulation. J Electromyogr Kinesiol. 2012;22(3):363-9, https://doi.org/10.1016/j.jelekin.2011.12.006.

18. Suica Z, Romkes J, Tal A, Maguire C. Walking with a four wheeled walker (rollator) significantly reduces EMG lower-limb muscle activity in healthy subjects. J Bodyw Mov Ther. 2016;20(1):65-73, https://doi.org/10.1016/ j.jbmt.2015.06.002.

19. Padulo J, Tiloca A, Powell D, Granatelli G, Bianco A, Paoli A. EMG amplitude of the biceps femoris during jumping compared to landing movements. Springerplus. 2013;2(1):520, https://doi.org/10.1186/2193-1801-2-520.

20. Nevala N. Ergonomic comparison of a sit-stand workstation with a traditional workstation in visual display unit work. Ergon Open J. 2013;6(1):22-7, https://doi.org/

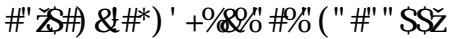

21. Dumas GA, Upjohn TR, Delisle A, Charpentier K, Leger A, Plamondon A, et al. Posture and muscle activity of pregnant women during computer work and effect of an ergonomic desk board attachment. Int J Ind Ergon. 2009;39(2): 313-25, https://doi.org/10.1016/j.ergon.2008.03.003.

22. Govindu NK, Babski-Reeves K. Reliability of thermal readings of the skin surface over the anterior deltoid during intermittent, overhead tapping tasks. Int J Ind Ergon. 2012;42(1):136-42, https://doi.org/10.1016/j.ergon. 2011.11.002.

23. Perotto A. Anatomical guide for the electromyographer: The limbs and trunk. 3rd ed. Springfield: Charles C Thomas; 1996. p. 66-89.

24. Thomas JS, Lavender SA, Corcos DM, Andersson GB. Effect of lifting belts on trunk muscle activation during a suddenly applied load. Hum Factors. 1999;41(4):670-6, https://doi.org/10.1518/001872099779656662.

25. Lee D-K, Kang M-H, Kim J-W, Kim Y-G, Park J-H, Oh J-S. Effects of non-paretic arm exercises using a tubing band on abdominal muscle activity in stroke patients. NeuroRehabilitation. 2013;33(4):605-10, https://doi.org/10.3233/ NRE-131003.

26. Craig CE, Goble DJ, Doumas M. Proprioceptive acuity predicts muscle co-contraction of the tibialis anterior and gastrocnemius medialis in older adults' dynamic postural control. Neuroscience. 2016;322:251-61, https://doi. org/10.1016/j.neuroscience.2016.02.036.

27. Allison GT, Marshall RN, Singer KP. EMG signal amplitude normalization technique in stretch-shortening cycle movements. J Electromyogr Kinesiol. 1993;3(4):236-44, https:// doi.org/10.1016/1050-6411(93)90013-M.

28. Babski-Reeves K, Stanfield J, Hughes L. Assessment of video display workstation set up on risk factors associated with the development of low back and neck discomfort.
Int J Ind Ergon. 2005; 35(7):593-604, https://doi.org/10. 1016/j.ergon.2005.01.006.

29. Tiainen S, Ropponen A, Louhevaara V. A quasi-experimental study of the effects of the erggi action model of musculoskeletal symptoms and VDU working conditions among university staff. Int J Occup Safety Ergon. 2014;20(4): 617-26, https://doi.org/10.1080/10803548.2014.11077070.

30. Balasubramanian V, Adalarasu K, Regulapati R. Comparing dynamic and stationary standing postures in an assembly task. Int J Ind Ergon. 2009;39(5):649-54, https://doi. org/10.1016/j.ergon.2008.10.017.

31. Cote JN, Hoeger Bement MK. Update on the relation between pain and movement: Consequences for clinical practice. Clin J Pain. 2010;26(9):754-62, https://doi. org/10.1097/AJP.0b013e3181e0174f.

32. Marras WS, Parakkat J, Chany AM, Yang G, Burr D, Lavender SA. Spine loading as a function of lift frequency, exposure duration, and work experience. Clin Biomech. 2006;21(4):345-52, https://doi.org/10.1016/j.clinbiomech. 2005.10.004.

33. Stauber WT. Factors involved in strain-induced injury in skeletal muscles and outcomes of prolonged exposures. J Electromyogr Kinesiol. 2004;14(1):61-70, https://doi. org/10.1016/j.jelekin.2003.09.010.

34. Lin YH, Chen CY, Cho MH. Effectiveness of leg movement in reducing leg swelling and discomfort in lower extremities. Appl Ergon. 2012;43(6):1033-7, https://doi. org/10.1016/j.apergo.2012.03.002.

35. Van Dieën JH, Oude Vrielink HH. Evaluation of work-rest schedules with respect to the effects of postural workload in standing work. Ergonomics. 1998;41(12):1832-44, https:// doi.org/10.1080/001401398186009.

36. Strimpakos N, Georgios G, Eleni K, Vasilios K, Jacqueline $\mathrm{O}$. Issues in relation to the repeatability of and correlation between EMG and Borg scale assessments of neck muscle fatigue. J Electromyogr Kinesiol. 2005;15(5):45265, https://doi.org/10.1016/j.jelekin.2005.01.007.

37. Gray H. Gray's anatomy: The classic collector's edition. Pick TP, Howden R, editors. New York: Bounty Books; 1977.

38. Krogh-Lund C, Jorgensen K. Myo-electric fatigue manifestations revisited: Power spectrum, conduction velocity, and amplitude of human elbow flexor muscles during isolated and repetitive endurance contractions at 30\% maximal voluntary contraction. Eur J Appl Physiol. 1993;66(2):161-73, https://doi.org/10.1007/BF01427058.

39. Babski-Reeves K, Stanfield J, Hughes L. Assessment of video display workstation set up on risk factors associated with the development of low back and neck discomfort. Int J Ind Ergon. 2005;35(7):593-604, https://doi.org/10.10 16/j.ergon.2005.01.006. 
40. Ekpenyong CE, Inyang UC. Associations between worker characteristics, workplace factors, and work-related musculoskeletal disorders: A cross-sectional study of male construction workers in Nigeria. Int J Occup Safety Ergon. 2014;20(3):447-62, https://doi.org/10.1080/10803548.20 14.11077057 .

41. Kim JH, Suh BS, Kim SG, Kim WS, Shon YI, Son HS. Risk factors of work related upper extremity musculoskeletal disorders in male cameramen. Ann Occup Environ Med. 2015;27(1):5, https://doi.org/10.1186/s40557-014-0052-x.

42. Mork PJ, Vik KL, Moe B, Lier R, Bardal EM, Nilsen TIL. Sleep problems, exercise and obesity and risk of chronic musculoskeletal pain: The Norwegian HUNT study. Eur J Public Health. 2014;24(6):924-9, https://doi.org/10.1093/ eurpub/ckt198.

43. Le P, Rose J, Knapik G, Marras WS. Objective classification of vehicle seat discomfort. Ergonomics. 2014;57(4):536-44, https://doi.org/10.1080/00140139.2014.887787.

44. Blangsted AK, Hansen K, Jensen C. Muscle activity during computer-based office work in relation to self-reported job demands and gender. Eur J Appl Physiol. 2003;89(3): 352-8, https://doi.org/10.1007/s00421-003-0805-7.

45. Karlqvist L, Tornqvist EW, Hagberg M, Hagman M, Toomingas A. Self-reported working conditions of VDU ope- rators and associations with musculoskeletal symptoms: A cross-sectional study focussing on gender differences. Int J Ind Ergon. 2002;30(4-5):277-94, https://doi.org/ $10.1016 / \mathrm{S} 0169-8141(02) 00131-2$.

46. Wigaeus Tornqvist E, Hagberg M, Hagman M, Hansson Risberg E, Toomingas A. The influence of working conditions and individual factors on the incidence of neck and upper limb symptoms among professional computer users. Int Arch Occup Environ Health. 2009;82(6):689-702, https://doi.org/10.1007/s00420-009-0396-7.

47. Woods M, Babski-Reeves K. Effects of negatively sloped keyboard wedges on risk factors for upper extremity work-related musculoskeletal disorders and user performance. Ergonomics. 2005;48(15):1793-808, https://doi. org/10.1080/00140130500292087.

48. Werth A, Babski-Reeves K. Effects of portable computing devices on posture, muscle activation levels and efficiency. Appl Ergon. 2014;45(6):1603-9, https://doi.org/10.1016/ j.apergo.2014.05.008.

49. Xu X, McGorry RW. The validity of the first and second generation Microsoft KinectTM for identifying joint center locations during static postures. Appl Ergon. 2015;49:47-54, https://doi.org/10.1016/j.apergo.20 15.01.005.

This work is available in Open Access model and licensed under a Creative Commons Attribution-NonCommercial 3.0 Poland License / Ten utwór jest dostępny w modelu open access na licencji Creative Commons Uznanie autorstwa - Użycie niekomercyjne 3.0 Polska - http://creativecommons.org/ licenses/by-nc/3.0/pl/deed.en. 